\title{
ENHANCEMENT OF UPFC PERFORMANCE WITH MATRIX CONVERTER USING ADVANCED DIRECT POWER CONTROL METHOD
}

\author{
Harika Badeti ${ }^{1}$, M.Sridhar ${ }^{2}$ \\ ${ }^{I}$ PG Scholar, ${ }^{2}$ Professor \& HOD, Dept of EEE, GIET College Rajahmundry, AP India
}

\begin{abstract}
In this paper presents a direct power control (DPC) for three-phase matrix converters operating as unified power flow controllers (UPFCs). Matrix converters (MCs) allow the direct aclac power conversion without dc energy storage links; therefore, the MC-based UPFC (MC-UPFC) has reduced size and cost, reduced capacitor power losses, together with higher reliability. Theoretical principles of direct power control (DPC) based on sliding mode control methods are established for an MC-UPFC dynamic model including the input filter. As a result, line active and reactive power, together with ac supply reactive power, can be directly controlled by selecting an appropriate matrix converter switching state assuring good steady-state and dynamic responses. Experimental results of DPC controllers for MC-UPFC show decoupled active and reactive power control, zero steady-state tracking error, and fast response times. Compared to an MC-UPFC using active and reactive power linear controllers based on a modified Venturini high-frequency $P W M$ modulator, the experimental results of the advanced DPC-MC guarantee faster responses without overshoot and no steady-state error, presenting no cross-coupling in dynamic and steady-state responses.
\end{abstract}

Keywords: Ac/ac conversion advanced direct power controller, matrix converter, unified power flow controller.

\section{INTRODUCTION}

Electric power flow through an alternating current transmission line is a function of the line impedance, the magnitudes of the sending-end and receiving-end voltages, and the phase angle between these voltages. Essentially, the power flow is dependent on the voltage across the line impedance. Electricity market deregulation, together with growing economic, environmental, and social concerns, has increased the difficulty to burn fossil fuels, and to obtain new licenses to build transmission lines (rights-of-way) and highpower facilities. This situation started the growth of decentralized electricity generation (using renewable energy resources). Unified power-flow controllers (UPFC) enable the operation of power transmission networks near their maximum ratings, by enforcing power flow through well-defined lines [2]-[4]. These days, UPFCs are one of the most versatile and powerful flexible ac transmission systems (FACTS) devices.

The existence of a dc capacitor bank originates additional losses, decreases the converter lifetime, and increases its weight, cost, and volume. In the last few decades, an increasing interest in new converter types, capable of performing the same functions but with reduced storage needs, has arisen [10]-[12]. These converters are capable of performing the same ac/ac conversion, allowing bidirectional power flow, guaranteeing near sinusoidal input and output currents, voltages with variable amplitude, and adjustable power factor [13]-[14]. These minimum energy storage ac/ac converters have the capability to allow independent reactive control on the UPFC shunt and series converter sides, while guaranteeing that the active power exchanged on the UPFC series connection is always supplied/absorbed by the shunt connection. Conventional UPFC controllers do not guarantee robustness [6]-[8] and [11], [12]. In [10], the dependence of the matrix converter output voltage on the modulation coefficient was investigated, concluding that MC-UPFC is able to control the full range of power flow. Recent nonlinear approaches [5] enabled better tuning of PI controller parameters. Still, there is room to further improve the dynamic response of UPFCs, using nonlinear robust controllers.

In the last few years, direct power control techniques have been used in many power applications, due to their simplicity and good performance [12]. In this paper, a matrix converterbased UPFC is proposed, using a direct power control approach (DPC-MC) based on an MC-UPFC dynamic model(Section II). In order to design UPFCs, presenting robust behaviour to parameter variations and to disturbances, the proposed DPC-MC control method, in Section III, is based on sliding mode-control techniques [9], allowing the real-time selection of adequate matrix vectors to control input and output electrical power. Sliding mode-based DPC-MC controllers can guarantee zero steady-state errors and no overshoots, good tracking performance, and fast dynamic 
responses, while being simpler to implement and requiring less processing power, when compared to proportionalintegral (PI) linear controllers obtained from linear active and reactive power models of UPFC using a modified Venturing high-frequency PWM modulator.

The dynamic and steady-state behaviour of the proposed DPCMC P, Q control method is evaluated and discussed using detailed simulations and experimental implementation (Sections IV and V). Simulation and experimental results obtained with the nonlinear DPC for matrix converter-based UPFC technology show decoupled series active and shunt/series reactive power control, zero steady-state error tracking, and fast response times, presenting faultless dynamic and steady-state responses.

\section{UPFC POWER SYSTEM}

A simplified power transmission network using the proposed matrix converter UPFC is presented in Fig. 1, Fig. 2 shows the simplified three-phase equivalent circuit of the matrix UPFC transmission system model. For system modelling, the power sources and the coupling transformers are all considered ideal. Also, the matrix converter is considered ideal and represented as a controllable voltage source, with amplitude $V_{C}$ and phase $\rho$. In the equivalent circuit, $V_{R O}$ is the load bus voltage; The DPC-MC controller will treat the simplified elements as disturbances.

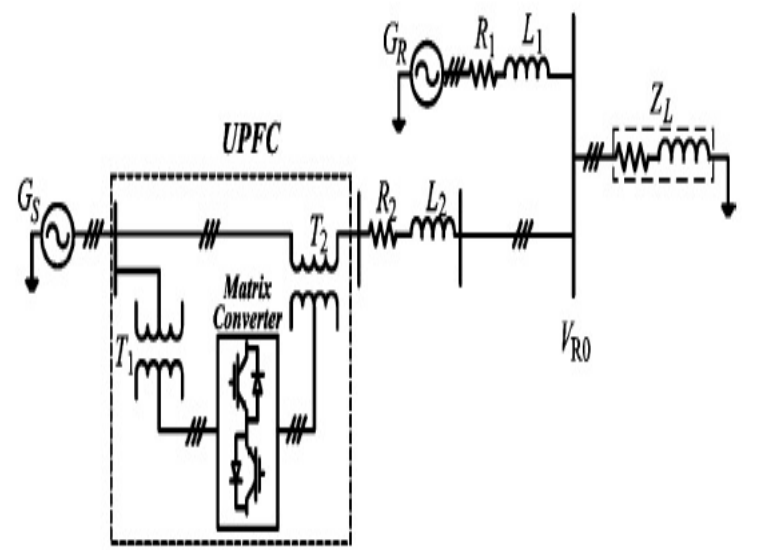

Fig 1: Transmission network with matrix converter UPFC.

Where $V_{S}$ and $V_{R}$ are, respectively, the sending-end and receiving-end sinusoidal voltages of the $G_{S}$ and $G_{R}$ generators feeding $\operatorname{load} Z_{L}$. The matrix converter is connected to transmission line 2, represented as a series inductance with series resistance $\left(L_{2}\right.$ and $\left.R_{2}\right)$, through coupling transformers $T_{1}$ and $T_{2}$.

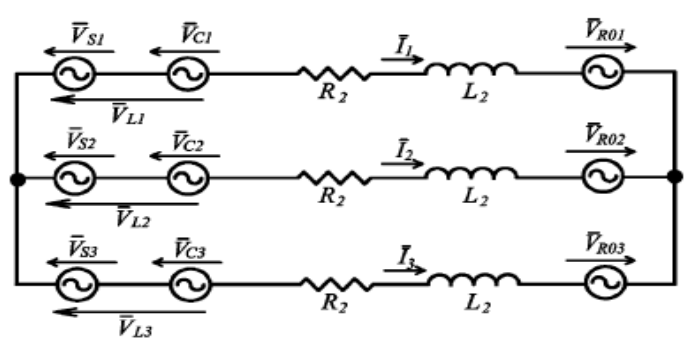

Fig 2: Three-phase equivalent circuit of the matrix UPFC and transmission line.

Considering a symmetrical and balanced three-phase system and applying Kirchhoff laws to the three-phase equivalent circuit (Fig. 2), the ac line currents are obtained in dq coordinates.

$$
\begin{aligned}
& \frac{d I_{d}}{\mathrm{dt}}=\omega I_{q}-\frac{R_{2}}{L_{2}} I_{d}+\frac{1}{L_{2}}\left(V_{L d}-V_{R 0 d}\right) \\
& \frac{d I_{q}}{\mathrm{dt}}=-\omega I_{d}-\frac{R_{2}}{L_{2}} I_{q}+\frac{1}{L_{2}}\left(V_{L q}-V_{R 0 q}\right) .
\end{aligned}
$$

The active and reactive power of sending end generator [9] are given in dq coordinates by

$$
\left[\begin{array}{l}
P \\
Q
\end{array}\right]=\left[\begin{array}{cc}
V_{d} & V_{q} \\
V_{q} & -V_{d}
\end{array}\right]\left[\begin{array}{c}
I_{d} \\
I_{q}
\end{array}\right]
$$

Assuming $V_{R O d}$ and $V_{s d}=V_{d}$ as constants and a rotating reference frame synchronized to the $V_{S}$ source so that $V_{S q}=0$, active and reactive power $\mathrm{P}$ and $\mathrm{Q}$ are given by (4) and (5), respectively.

Based on the desired active and reactive power $\left(P_{\text {ref }}, Q_{\text {ref }}\right)$, reference currents $\left(I_{\text {dref }}, I_{\text {qref }}\right)$ can be calculated from (4) and (5) for current controllers [20]. However, allowing P, Q actual powers are sensitive to errors in the $V_{d}, V_{q}$ values.

\subsection{Matrix Converter Output Voltages and Input Currents}

A diagram of the UPFC system (Fig. 3) includes the threephase shunt input transformer (with windings $\mathrm{Ta}, \mathrm{T}_{\mathrm{b}}, \mathrm{T}_{\mathrm{c}}$ ), the three-phase series output transformer (with windings $T_{A}, T_{B}$, $T_{C}$ ) and the three-phase matrix converter, represented as an array of nine bidirectional switches $S_{\mathrm{kj}}$ with turn-on and turnoff capability, allowing the connection of each one of three output phases directly to any one of the three input phases. The three-phase $(\mathrm{CCr})$ input filter is required to re-establish a voltage-source boundary to the matrix converter, enabling smooth input currents. 


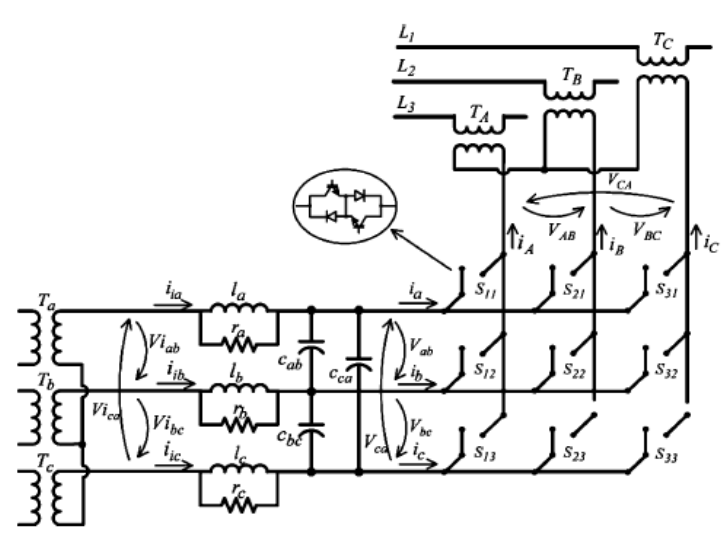

Fig 3: Transmission network with matrix converter UPFC.

Applying dq coordinates to the input filter state variables presented in Fig. 3 and neglecting the effects of the damping resistors, the following equations are obtained:

$$
\left\{\begin{array}{l}
\frac{d i_{i d}}{\mathrm{dt}}=\omega i_{i q}-\frac{1}{2 l} V_{d}-\frac{1}{2 \sqrt{3} l} V_{q}+\frac{1}{l} V_{i d} \\
\frac{d i_{i q}}{\mathrm{dt}}=-\omega i_{i d}+\frac{1}{2 \sqrt{3} l} V_{d}-\frac{1}{2 l} V_{q}+\frac{1}{l} V_{i q} \\
\frac{d V_{d}}{\mathrm{dt}}=\omega V_{q}-\frac{1}{2 \sqrt{3} C} i_{i q}+\frac{1}{2 C} i_{i d}-\frac{1}{2 C} i_{d}+\frac{1}{2 \sqrt{3} C} i_{q} \\
\frac{d V_{q}}{\mathrm{dt}}=-\omega V_{d}+\frac{1}{2 \sqrt{3} C} i_{i d}+\frac{1}{2 C} i_{i q}-\frac{1}{2 \sqrt{3} C} i_{d}-\frac{1}{2 C} i_{q}
\end{array}\right.
$$

Where $V_{\text {id }}, V_{\text {iq }}, I_{i d}, I_{i q}$ represents, input voltages and input current in dq components (at the shunt transformer secondary) and $V_{d}, V_{q}, I_{d}, I_{q}$, are matrix converter voltages and input currents in dq components, respectively.

\section{DIRECT POWER CONTROL OF MC-UPFC}

\subsection{Direct Control of Matrix Converters Input}

\section{Reactive Power}

In addition, the matrix converter UPFC can be controlled to ensure a minimum or a certain desired reactive power at the matrix converter input. Similar to the previous considerations, since the voltage source input filter (Fig. 3) dynamics (6) has a strong relative degree of two [25], then a suitable sliding surface $S_{Q i}\left(e_{Q i}, t\right)(19)$ will be a linear combination of the desired reactive power error $e_{Q i}=Q_{\text {iref }}-Q_{i}$ and its firstorder time derivative.

$$
S_{Q_{i}}\left(e_{Q_{i}}, t\right)=\left(Q_{i_{\mathrm{ref}}}-Q_{i}\right)+K_{Q_{i}} \frac{d}{\mathrm{dt}}\left(Q_{i_{\mathrm{ref}}}-Q_{i}\right) .
$$

The time derivative can be approximated by a discrete time difference, as $K_{Q i}$ has been chosen to obtain a suitable switching frequency, since as stated before, this sliding surface needs to be quantized only in two levels $(-1$ and +1$)$ using one hysteresis comparator.
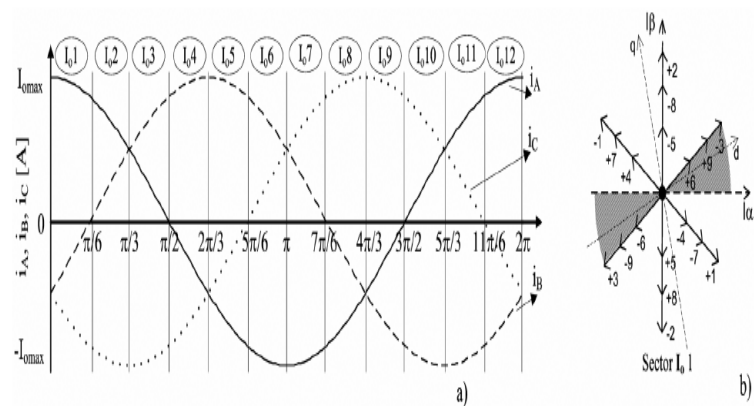

Fig 4: (a) Output currents and their corresponding sector. (b) Input current state-space vectors, when output currents are located at sector $\mathrm{I}_{01}$. The axis is represented, considering that the input voltages are located in zone $\mathrm{V}_{01}$.

To full fill a stability condition similar to (15), considering the input filter dynamics (6), (20) is obtained.

$$
\begin{aligned}
& \dot{S}_{Q i}\left(e_{Q i}, t\right)= \\
& V_{i d}\left(\frac{\mathrm{di}_{i q}}{\mathrm{dt}}+K_{Q i} \frac{\mathrm{d}^{2} \mathrm{i}_{i q}}{\mathrm{dt}^{2}}\right)=V_{i d}\left(-\omega i_{i d}+\frac{1}{2 \sqrt{3} l} V_{d}-\frac{1}{2 l} V_{q}\right)+ \\
& V_{i d} K_{Q i}\left(-\omega^{2} i_{i q}+\frac{\omega}{l} V_{d}+\frac{\omega}{\sqrt{3} l} V_{q}-\frac{\omega}{l} V_{i d}-\frac{i_{i q}}{3 l C}+\frac{i_{q}}{3 l C}\right) .
\end{aligned}
$$

From (20), it is seen that the control input, the $i_{q}$ matrix input current, must have enough amplitude to impose the sign of $S_{Q i}\left(e_{Q i}, t\right)$ Supposing that there is enough $i_{q}$ amplitude, (9) and (12) are used to establish the criteria (13) to choose the adequate matrix input current vector that imposes the needed sign of the matrix input-phase current $i_{q}$ related to the outputphase currents by (9).

1. If $S_{Q i}\left(e_{Q i}, t\right)>0 \Rightarrow S_{Q i}\left(e_{Q i}, t\right)<0$, then select vector with current $i_{q}<0$ to increase $Q_{i}$.

2. If $S_{Q i}\left(e_{Q i}, t\right)<0 \Rightarrow S_{Q i}\left(e_{Q i}, t\right)>0$, then select vector with current $i_{q}>0$ to increase $Q_{i}$.

The sliding mode is reached when vectors applied to the converter have the necessary $i_{q}$ current amplitude to satisfy stability conditions, such as (15). Therefore, to choose the most adequate vector in the chosen dq reference frame, it is necessary to know the output currents location since the $i_{q}$ input current depends on the output currents (Table I). Considering that the dq -axis location is synchronous with the $\mathrm{V}_{\text {ia }}$ input voltage (i.e., reference frame depends on the $\mathrm{V}_{\text {ia }}$ input voltage location), the sign of the matrix reactive power $\mathrm{Q}_{\mathrm{i}}$ can be determined by knowing the location of the input voltages and the location of the output currents (Fig.4). 
Table 1: State-space vectors selection, for input voltages located at sector $\mathrm{v}_{\mathrm{i}} 1$

\begin{tabular}{|c|c|c|c|c|c|c|c|c|c|c|c|c|c|}
\hline \multirow{3}{*}{$C_{\alpha} \quad C_{\beta}$} & \multicolumn{13}{|c|}{ Sector } \\
\hline & & $\begin{array}{l}12 ; \\
C_{0}\end{array}$ & & & & lit & 1,5 & $I_{0} 6$ & $I_{0} 7$ & & $; I_{0}{ }^{9}$ & & $; I_{0} l l$ \\
\hline & + & & 1 & +1 & 1 & +1 & -1 & +1 & -1 & +1 & -1 & +1 & -1 \\
\hline$-1+$ & . & 9 & 7 & .9 & +7 & .9 & +7 & +7 & .9 & +7 & -9 & +7 & .9 \\
\hline & + & 3 & 1 & +3 & -1 & .1 & +3 & -1 & +3 & -1 & +3 & +3 & -1 \\
\hline & - & 6 & -4 & +4 & .6 & +4 & -6 & +4 & -6 & -6 & +4 & -6 & +4 \\
\hline & . & 9 & 7 & .9 & +7 & 9 & +7 & +7 & .9 & +7 & 9 & +7 & .9 \\
\hline & . & & 2 & +8 & .8 & .5 & +5 & +2 & .2 & .8 & +8 & +5 & .5 \\
\hline & . & 7 & & .7 & +9 & .7 & +9 & +9 & .7 & +9 & .7 & +9 & .7 \\
\hline & . & & 6 & +6 & 4 & +6 & -4 & +6 & 4 & -4 & +6 & -4 & +6 \\
\hline & & & 3 & +1 & .3 & .3 & +1 & .3 & +1 & .3 & +1 & +1 & .3 \\
\hline & . & & & .7 & +9 & .7 & +9 & +9 & .7 & +9 & .7 & +9 & .7 \\
\hline
\end{tabular}

\section{SIMULATION RESULTS}

The performance of the proposed direct control system was evaluated with a detailed simulation model using the MATLAB/SIMULINK SIMPOWERSYSTEMS to represent the matrix converter, transformers, sources and transmission lines, and SIMULINK blocks to simulate the control system. Ideal switches were considered to simulate matrix converter semiconductors minimizing simulation times.

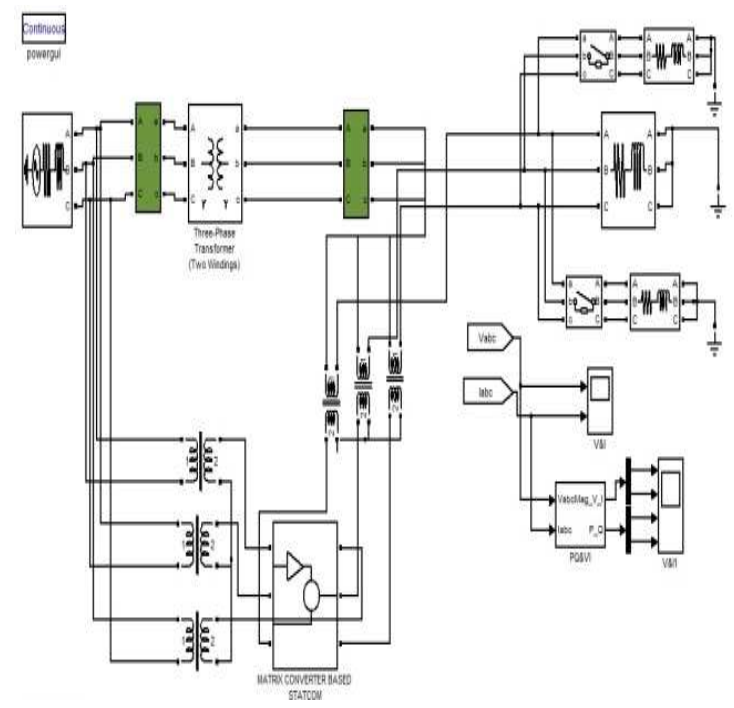

Fig 5: Modeling circuit of the three-phase matrix converter operating as a UPFC with direct power control.

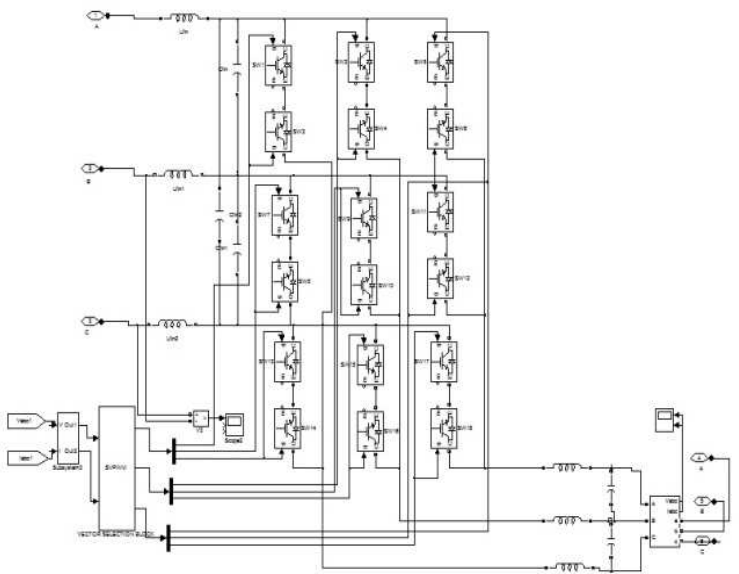

Fig 6: Control scheme of direct power control of the threephase matrix converter.

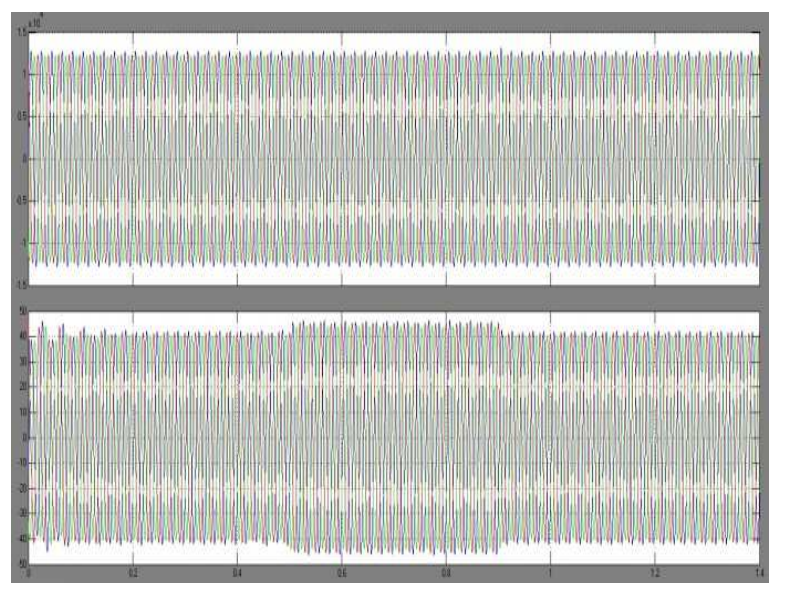

Fig 7: SIMULINK results of proposed UPFC (a) Output voltage, (b) Output current.

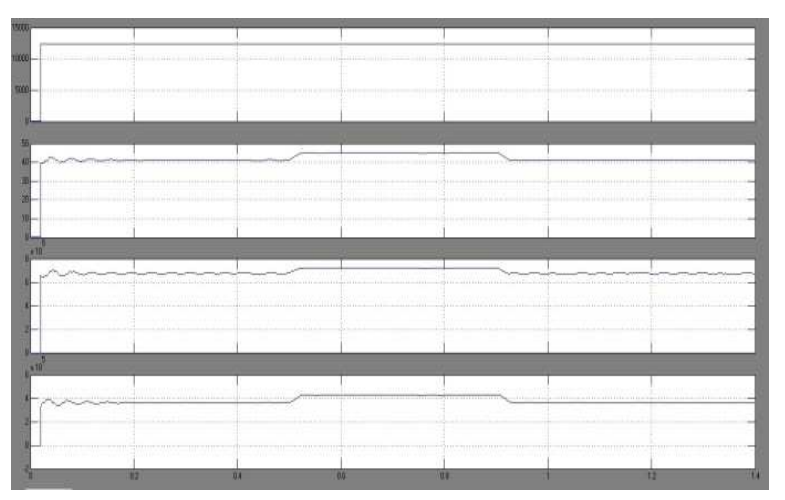

Fig 8: SIMULINK results of proposed UPFC (a) magnitude of Output voltage, (b) Magnitude of output current, (c) Real power, (d) Reactive power 


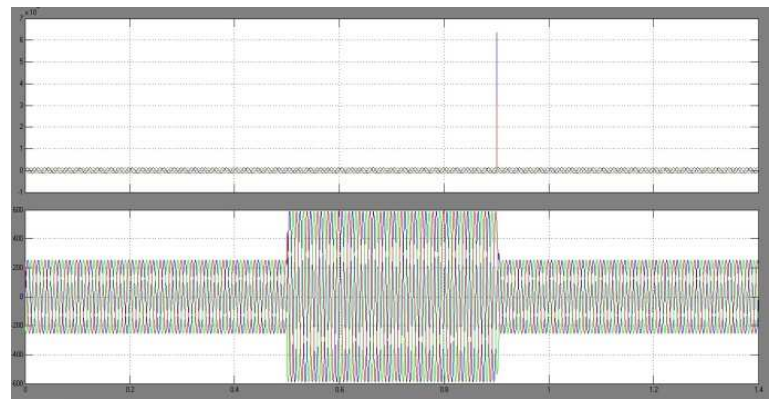

Fig 9: SIMULINK results of without UPFC (a) Output Voltage, (b) output current.

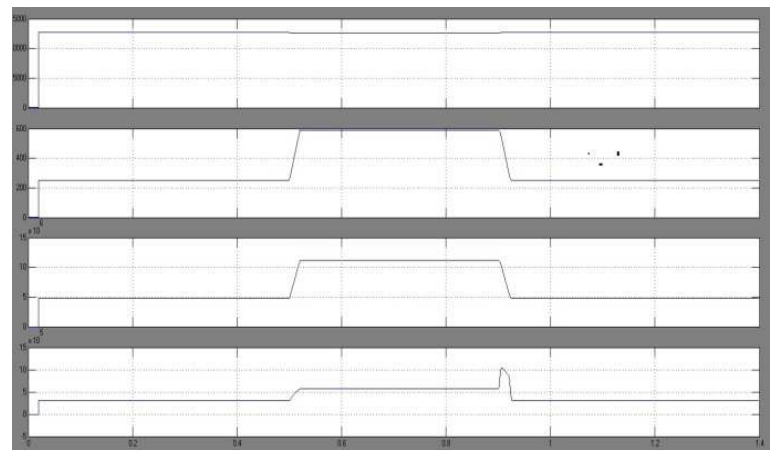

Fig 10: SIMULINK results of without UPFC (a) Magnitude of output voltage, (b) Magnitude of output current, (c) real power, (d) reactive power.

Simulation results confirm the performance of the proposed controllers, showing no cross-coupling, no steady-state error (only switching ripples), and fast response times for different changes of power references. The results (Fig. 7) also show fast response without cross coupling between active and reactive power. This confirms the DPC-MC robustness to input filter parameter variation, the ability to operate at low switching frequencies, and insensitivity to switching nonlinearity.

\section{CONCLUSIONS}

In this Presented simulation results show that active and reactive power flow can be advantageously controlled by using the proposed DPC. Results show no steady-state errors, no cross-coupling, insensitivity to non-modeled dynamics and fast response times, thus confirming the expected performance of the presented nonlinear DPC methodology. The obtained DPC-MC results were compared to PI linear active and reactive power controllers using a modified Venturini highfrequency PWM modulator. Despite showing a suitable dynamic response, the PI performance is inferior when compared to DPC. Furthermore, the PI controllers and modulator take longer times to compute.

\section{REFERENCES}

[1] S. M. Metev and V. P. Veiko, Laser Assisted Microtechnology, 2nd ed., R. M. Osgood, Jr., Ed. Berlin, Germany: Springer-Verlag, 1998.

[2] N. Hingorani and L. Gyugyi, Understanding FACTSConcepts and Technology of Flexible AC Transmission Systems. Piscataway, NJ: IEEE Press/Wiley, 2000.J. Breckling, Ed.,

[3] L. Gyugyi, "Unified power flow control concept for flexible AC transmission systems," Proc. Inst. Elect. Eng. C, vol. 139, no. 4, Jul. 1992.

[4] C. Schauder, L. Gyugyi, M. Lund, D. Hamai, T. Rietman, D. Torgerson, and A. Edris, "Operation of the unified power flow controller (UPFC) under practical constraints," IEEE Trans. Power Del., vol. 13, no. 2, pp.630-639, Apr. 1998.

[5] F. Gao and M. Iravani, "Dynamic model of a space vector modulated matrix converter," IEEE Trans. Power Del., vol. 22, no. 3, pp. 1696-1750, Jul. 2007.

[6] B. Geethalakshmi and P. Dananjayan, "Investigation of performance of UPFC without DC link capacitor," in Elect. Power Energy Res.. New York: Elsevier, 2008, pp. 284-294, 736-746.

[7] X. Jiang, X. Fang, J. Chow, A. Edris, E. Uzunovic, M. Parisi, and L. Hopkins, "A novel approach for modeling voltage-sourced converterbased FACTS controllers," IEEE Trans. Power Del., vol. 23, no. 4, pp. 2591-2598, Oct. 2008.

[8] R. Strzelecki, A. Noculak, H. Tunia, and K. Sozanski, "UPFC with matrix converter," presented at the EPE Conf., Graz, Austria, Sep. 2001.

[9] J. Silva and S. Pinto, , M. H. Rashid, Ed., "Power Electronics Handbook," in Control Methods for Switching Power Converters, 2nd ed. New York: Academic Press/ Elsevier, 2007, ch. 34, pp. 935-998.R. E. Sorace,

[10] W. S. Levine, The Control Handbook. Boca Raton, FL: CRC, 1996,

[11] I. Martins, J. Barros, and J. Silva, "Design of crosscoupling free current mode controller for UPFC series converter," in Proc. IEEE Optimization of Electrical and Electronic Equipment Conf., May 2008, pp. 209218.pp. 911-912.

[12] H. Akagi, Y. Kanazawa, and A. Nabae, "Instantaneous reactive power compensators comprising switching devices without energy storage components," IEEE Trans. Ind. Appl., vol. IA-20, no. 3, pp. 625-630, May/Jun. 1984.V. S. Reinhardt, and S. A. Vaughn, "High-speed digital-to-RF converter," U.S. Patent 5 668 842, Sept. 16, 1997. (2002) The IEEE website. [Online]. Available: http://www.ieee.org/

[13] P. Wheeler, J. Rodriguez, J. Clare, L. Empringham, and A. Weinstein, "Matrix converters: A technology review," IEEE Trans. Ind. Electron.,vol. 49, no. 2, pp. 276-288, Apr. 2002. 
[14] A. Alesina and M. G. B. Venturini, "Solid-state power conversion: A Fourier analysis approach to generalized transformer synthesis," IEEE Trans. Circuits Syst., vol. CAS-28, no. 4, pp. 319-330, Apr. 1981.

[15] J. Monteiro, J. Silva, S. Pinto, and J. Palma, "Unified power flow controllers without DC bus: Designing controllers for the matrix converter solution," presented at the Int. Conf. Electrical Engineering, Coimbra, Portugal, 2005. 